\title{
MODERNIZAÇÃO DA ADVOCACIA: A FLEXIBILIZAÇÃO DO ADVOGADO CONTEMPORÂNEO E A IMPORTÂNCIA DAS IMPLICAÇÕES DA LEI N. 8.906/94 NA PRESERVAÇÃO DO PENSAMENTO CRÍTICO
}

\section{RESUMO}

O presente artigo possui como objeto analisar a modernização da advocacia através do atual modelo de flexibilização que o advogado contemporâneo tem que adotar para se sustentar na profissão e a importância das implicações da Lei n. 8.906/94 na preservação do pensamento crítico, preceitos morais subjetivos e condutas éticas. A advocacia contemporânea evoluiu em relação ao modelo clássico, sendo fruto de uma transformação social que resultou na necessária adequação à informatização corrente. Por outro lado, o gradativo aumento de profissionais no mercado, pautados justamente pela acessibilidade e informatização, tem induzido uma possível mercantilização da profissão através da publicidade desenfreada de informações e da produção mecanizada dos processos, desestimulando o senso crítico. O método de pesquisa foi o indutivo e o procedimento, monográfico. Utilizou-se também a técnica da pesquisa bibliográfica para fundamentação.

Palavras-chave: Advocacia. Informatização. Ética. Modernização. Pensamento crítico. Transformação social.

\section{ADVOCACY IMPROVEMENT: THE FLEXIBILIZATION OF THE CONTEMPORARY LAWYER AND THE IMPORTANCE OF THE IMPLICATIONS OF LAW 8.906 / 94 IN PRESERVATION OF CRITICAL THOUGHT}

\begin{abstract}
This article aims to analyze the modernization of advocacy through the current model of flexibility which the contemporary lawyer has to adopt to support his profession, and the importance of the implications of Law no. 8.906 / 94 in the preservation of critical thinking, subjective moral precepts and ethical conduct. Contemporary advocacy evolved in relation to the classical model, being the fruit of a social transformation, which has resulted in the necessary adaptation to the current computerization. On the other hand, the gradual increase of professionals in the market, based precisely on accessibility and computerization, has induced a possible commercialization of the profession through the unbridled advertising of information and the mechanized production of the processes, discouraging the critical sense. The research method was the inductive one and the procedure was monographic. We also used the technique of bibliographical research for foundation. The Final Considerations show the most relevant aspects to the theme, proving, or not, the basic hypothesis.
\end{abstract}

Keywords: Advocacy. Informatization. Ethic. Modernization. Critical Thinking. Social transformation.

\footnotetext{
${ }^{1}$ Assessor Jurídico da Vara da Fazenda Pública, Acidentes do Trabalho e Registros Públicos da Comarca de Rio do Sul - Santa Catarina; Pós-Graduando em Direito Civil pela Faculdade Metropolitana de Rio do Sul UNIASSELVI; Pós-Graduando em Direito Penal pela Faculdade Metropolitana de Rio do Sul - UNIASSELVI. Autor de Artigos Jurídicos publicados em periódicos impressos de circulação nacional e on-line. E-mail: alaniagokistner@gmail.com.

${ }^{2}$ Advogado atuante em Blumenau/SC - OAB/SC 25091; Membro efetivo do Instituto dos Advogados de Santa Catarina - IASC; Mestre em Ciência Jurídica pela Universidade do Vale do Itajaí - UNIVALI; Pós-Graduado em Direito Processual Civil pelo Instituto Catarinense de Pós-Graduação - ICPG; Graduado em Direito pelo Centro de Educação Superior de Blumenau - CESBLU; Graduado em Tecnólogo em Processamento de Dados a Nível Superior pela Universidade Regional de Blumenau - FURB; Professor Universitário, Titular no Curso de Direito do Centro Universitário para o Desenvolvimento do Alto Vale do Itajaí - UNIDAVI (Graduação e PósGraduação lato sensu); Membro do Grupo de Pesquisa Estado, Constitucionalismo e Produção do Direito da Universidade do Vale do Itajaí - UNIVALI; Editor Responsável e Membro do Conselho Editorial da Revista Direito UNIDAVI [ISSN 2177-2991]; Autor de Livros e de Artigos Jurídicos publicados em periódicos impressos de circulação nacional e on-line. E-mail: saulbusnello@ hotmail.com.
} 


\section{INTRODUÇÃO}

O presente artigo tem por objetivo geral propiciar uma análise da modernização da advocacia através da flexibilização da profissão no cenário contemporâneo, resultado do avanço da tecnologia e da informatização, bem como investigar as implicações do Estatuto da Advocacia nessa nova forma de trabalho e na preservação do pensamento crítico diante de uma eventual mercantilização.

Como objetivos específicos, tem-se: a) analisar o histórico da advocacia no Brasil; b) pontuar os desafios históricos enfrentados pela advocacia no cenário nacional; c) comentar a adequação constitucional do Estatuto da Advocacia; d) estudar a importância da advocacia para a garantia do devido acesso à justiça; e) pesquisar como a mercantilização da advocacia desestimula o senso crítico; e f) explicitar os fatores que resultaram em uma mercantilização subjetiva da profissão.

O tema proposto pauta-se na necessidade de avaliar as implicações do processo de informatização da advocacia no contexto moral subjetivo e nas condutas éticas aplicadas pela deontologia jurídica. Tal tema é contemporâneo e possibilita uma idealização dos impactos sociais que o mau uso da informatização pode trazer à advocacia.

Como questionamento, levanta-se o seguinte problema: a Lei n. 8.906/94 assegura a preservação do pensamento crítico da advocacia moderna no que diz respeito à flexibilização do advogado contemporâneo?

Para delimitação do tema, supõe-se que a flexibilização do advogado contemporâneo ante as implicações da Lei n. 8.906/94 é fundamental para a preservação do pensamento crítico na advocacia moderna.

O método de pesquisa utilizado é o indutivo, e o procedimento adotado é o monográfico.

Inicialmente, propõe-se realizar um estudo acerca do histórico da advocacia no Brasil, analisando-se a forma como o advogado era retratado no período Brasil-Império, assim como a emancipação e conquista da independência profissional através da criação do Instituto dos Advogados do Brasil, que posteriormente viria a se tornar a Ordem dos Advogados do Brasil. 
Seguidamente, passa-se a analisar os desafios enfrentados pela advocacia no contexto nacional, sobretudo os fatores que resultaram na participação da OAB e das Associações nas lutas em prol da democracia e das garantias mínimas que viriam a ser positivadas na Constituição da República Federativa do Brasil de 1988. Com isso, pontuar-seão as implicações que a nova Carta constitucional trouxe ao Estatuto da Advocacia e a necessária adequação ao contexto social, político e jurídico vivenciado a partir desse ponto.

Mais à frente, analisa-se a importância da advocacia como instrumento para garantia do acesso à justiça não apenas no sentido figurativo do termo, mas em seu sentido literal, materializado através da entrega de uma prestação jurisdicional satisfatória e justa, baseada nos fatos, elementos de fato e elementos jurídicos que cada caso em particular apresenta.

Por fim, considerando a importância do advogado na sociedade - o qual atua como profissional idôneo e com independência primordial para possibilitar a concretude dos direitos e garantias mínimas à ampla defesa, ao contraditório e, acima de tudo, a um processo justo e igualitário -, buscar-se-á traçar uma análise de perspectiva acerca da modernização da advocacia e como o aumento de profissionais, alicerceado pela informatização, deve provocar a necessária atenção aos deveres que visam evitar a mercantilização da profissão, a concorrência desleal e a extinção do pensamento crítico pela mecanização em massa.

\section{COMPÊNDIO HISTÓRICO DA ADVOCACIA NO BRASIL}

O estudo acerca da modernização da advocacia remete à necessidade de avaliar o desenvolvimento no campo de atuação frente às incontáveis alterações sociais, econômicas e políticas que o Estado brasileiro enfrentou e segue enfrentando diariamente. A advocacia figura presente desde quando os cidadãos passaram a se organizar em sociedade e estabelecer os necessários julgamentos entre si, com o objetivo de avaliar as condutas praticadas, estabelecer regras e punir a todo modo as violações primordiais. Com o passar do tempo, a concretude normativa foi tão somente ganhando traços de previsibilidade, aumentando e alterando as tipificações.

O advogado, constituído na forma do profissional liberal, graduado em Direito e especialista no conhecimento jurídico, é peça fundamental para a administração da justiça, sendo intermediário na segurança e defesa dos interesses das partes em juízo. A essência da 
advocacia é, a todo modo, o pensamento crítico, a capacidade de questionar e raciocinar logicamente, o que possibilita a evolução social.

A regulamentação da advocacia no Brasil advém da institucionalização dos cursos jurídicos no antigo Brasil-Império. Quando D. Pedro I - movido pela forte tendência ocidental de constitucionalização, marcada principalmente pelos preceitos do commom law e civil lawresolve instalar a Assembleia Constituinte, nascem em 1823 os primeiros debates acerca dos estudos jurídicos no Brasil (D’ÁVILA, 2006). Para Gisela Gondim Ramos, a proclamação da independência do Brasil teve relevante importância na concepção da classe dos advogados e dos estudos jurídicos, possibilitando, inclusive, o rompimento com o monopólio português, ainda que muito do que se concebia sobre a Ciência Jurídica tivesse sido colhido da cultura colonizadora:

\begin{abstract}
Alguns passos atrás na história nos dão conta da importância dos fatos políticos que culminaram na proclamação da Independência do Brasil para a classe dos advogados. Destaca-se, acima de tudo, a proibição da Metrópole portuguesa de que se constituísse qualquer universidade em terras brasileiras. Não lhes interessava, por óbvio, que uma colônia sua pudesse criar condições para se auto-administrar. (RAMOS, 2003, p. 696-697).
\end{abstract}

Na análise de Thiago Cássio D’Ávila, a figura de José Feliciano Fernandes Pinheiro merece destaque no que concerne aos cursos jurídicos no Brasil. Com amplo conhecimento embasado na formação em Direito em Portugal, apresentou, ao atuar como Deputado Constituinte eleito pelo Rio Grande do Sul, proposta de criação dos cursos jurídicos no país (D’ÁVILA, 2006). A criação dos cursos jurídicos fez com que o Estado brasileiro desse um grande passo para sua independência institucional em relação aos países colonizadores e à sua cultura implantada - os primeiros advogados brasileiros, até então, formavam-se em Portugal, na Universidade de Coimbra, motivo pelo qual os países mantêm estrita relação até os dias atuais (D’ÁVILA, 2006)

Sérgio Sérvelu da Cunha comenta que, inicialmente e durante muito tempo, somente determinada classe privilegiada por situação econômica favorável é que conseguia frequentar os cursos jurídicos nas universidades, ou seja, havia indireta seletividade social:

Devendo formar os quadros da burocracia estatal, os primeiros advogados formados no Brasil eram os filhos dos grandes proprietários de terras, fazendeiros, produtores de cana e de café, que se incorporavam à perspectiva do poder. A partir de 1822, o Brasil era um Estado unitário, com sua capital no Rio de Janeiro. Enquanto o domínio hispânico da América do Sul se dividira em várias repúblicas regidas por Constituições liberais, e enquanto 
em Portugal, após a revolução do Porto, também se adotava uma Constituição liberal, a Independência brasileira se fizera em torno do herdeiro da coroa portuguesa, a quem se atribuiu o título de imperador. (CUNHA, 2005, p. 3-4).

Contudo, somente em 1843 foi fundado o Instituto dos Advogados Brasileiros, através de um aviso da Secretaria de Estado da Justiça - D. Pedro I, em sequência, aprovou os estatutos e regimento interno. Das lições de Sérgio Sérvulo da Cunha é possível verificar que: “O IAB exercia função predominantemente cultural, em grande parte restrita ao Rio de Janeiro, mas como órgão de representação política dos advogados desde o início lutou pela criação de uma ordem dos $\operatorname{advogados}^{3}$, que desse autonomia ao exercício da profíssão" (CUNHA, 2005, p. 4).

Embora o Brasil tivesse conquistado sua independência institucional, a dependência cultural e social em relação aos colonizadores continuou existindo intrinsecamente na sociedade. A própria ideia de constituição de uma "ordem" de advogados foi inspirada na dos portugueses, que em 23 de março de 1838 aprovaram os Estatutos da Associação dos Advogados de Lisboa, cujo objetivo, entre outros, era tecer articulação política para criação da Ordem dos Advogados de Portugal (OAP). Colhendo-se da organização portuguesa, Francisco Alberto Teixeira de Aragão, que era Conselheiro do Supremo Tribunal de Justiça (denominação dada à mais alta corte de justiça na época), propôs em similaridade a criação, no Brasil, de associação com preceitos originários, dando abertura à futura Ordem dos Advogados do Brasil (D’ÁVILA, 2006).

A partir de sua criação no início do governo Getúlio Vargas (em novembro de 1930), através dos Decretos n. 20.784/1931 e 22.478/1933, a Ordem dos Advogados do Brasil consolidou-se como órgão disciplinar que atua em defesa da classe dos advogados. Passou-se a admitir a inscrição de bacharéis em Direito e instituiu-se análise e aplicação de sanções pelas infrações éticas no exercício da profissão (CUNHA, 2005, p. 7-8). Atualmente, todo o regimento ético e disciplinar encontra-se legalmente instituído pelo Estatuto da Ordem dos

\footnotetext{
${ }^{3}$ No Direito Romano, já era possível perceber a existência da denominação "Ordo", ou seja, Ordem. Segundo Hélcio Maciel França Madeira, conceber organização dos Advogados na Roma Antiga é plenamente aceitável, levando-se em consideração a época: "as ordens ou corporações de advogados são independentes entre si, mas estão adstritas sempre a uma só jurisdição, cuja autoridade judiciária (e.g. praefectus praetorio, o governador de província, ou o prefeito augustal) exerce o poder de fiscalizá-las e, eventualmente, regulamentá-las. Em cada ordem os advogados seguem uma hierarquia conforme as datas de suas inscrições. Nos mais altos cargos encontram-se os primates, em seguida os outros statuti. Finalmente, há também os advogados estagiários (postulantes) que passam por um regime especial antes de adentrarem o ordo, na medida em que houver a saída de algum statutus (MADEIRA, 2002, p. 57-58)".
} 
Advogados do Brasil, disposto pela Lei n. 8.906/1994, que revogou a antiga Lei $n$. 4.215/1963, adequando a atividade jurídica aos preceitos constitucionalmente estabelecidos.

\subsection{Desafios Históricos da Advocacia e Adequação Constitucional da Atividade Jurídica Através da Lei n. 8.906, de 4 de Julho de 1994}

É possível observar que a advocacia ultrapassou uma série de desafios elementares que, a todo modo, fizeram com que a atividade jurídica evoluísse em todos os sentidos, seja no âmbito econômico, social ou político. Com isso, a própria advocacia precisou se adequar ao contexto jurídico, político e social que da sociedade.

De modo mais específico, o sentimento democrático consolidou a necessidade de adequação da vontade da nação aos preceitos normativos fundamentais, garantindo-se, através da Constituição Cidadã de 1988, uma série de direitos mínimos até então sem tipicidade identificada. A CRFB/88, como marco de um novo dogma constitucional, possibilitou aos cidadãos uma maior segurança acerca do enfrentamento estatal e sua interferência na vida privada, ao tempo em que introduziu obrigações estatais, como a garantia do acesso à justiça anteriormente mencionada.

Frente ao novo contexto social, a Lei n. 4.215/1963, que anteriormente contemplava o Estatuto da Ordem dos Advogados do Brasil, tornou-se obsoleta, uma vez que estava mais de 20 anos atrás do novo cenário pressuposto pela Constituição de 1988. O fortalecimento da sociedade fez com que fosse igualmente necessário o fortalecimento das garantias mínimas da advocacia, ora identificadas como "prerrogativas profissionais".

Tal evolução normativa justificou-se, de modo prático, com base nas incontáveis lutas democráticas da Ordem dos Advogados do Brasil pela proteção aos direitos humanos, até então em discussão no âmbito do regime ditatorial instalado com a Revolução de 1964. Segundo Thiago Cássio D’Ávila, entre as lutas sociodemocráticas da OAB, destaca-se sua:

[...] participação decisiva nas discussões jurídicas e políticas do país. Ressalte-se o "Movimento pela Ética na Política", fundado em documento entregue ao Presidente do Congresso Nacional, Nelson Carneiro, contra as medidas econômicas tomadas pelo Governo Fernando Collor. A OAB levantou-se ainda contra propostas de emendas constitucionais que colocariam em risco os ideais da Carta de 1988, e, diante das denúncias de corrupção do Governo Collor, ingressa no movimento favorável ao impeachment do Presidente da República, que posteriormente viria a renunciar. De destacar ainda a "Campanha pela ética nas eleições", lançada pela $\mathrm{OAB}$, por proposta de Márcio Thomaz Bastos, que preocupada com as eleições municipais de 1996, lançou, em 25 de junho daquele ano, uma 
campanha informativa com objetivos de incentivar o voto consciente pela população e a divulgação dos financiadores de campanha pelos candidatos. (D’ÁVILA, 2006, não paginado).

De modo geral, a OAB contou com a colaboração de diversas associações, sobretudo o Instituto dos Advogados do Estado de Santa Catarina, primeira e mais antiga Associação de Advogados do Estado, lutando incansavelmente pelo retorno da democracia durante o regime de Vargas, entre os anos de 1937 a 1945, e a ditadura militar, entre os anos de 1964 a 1980.

A sociedade moderna tem como requerimento essencial da justiça que toda a pessoa tenha a possibilidade de proteger seus interesses, e é nesse sentido que se apresenta o advogado, com um dos papéis mais importantes no cenário jurídico. $\mathrm{O}$ advogado, portanto, não só faz parte da administração da justiça, como tem um papel básico no seu desenvolvimento de forma efetiva. Enquanto membro de uma profissão jurídica, ao tempo em que representa o cliente, sendo um operador do sistema jurídico e cidadão componente da sociedade, tem especial responsabilidade por manter a idoneidade do sistema da justiça (RAMOS, 2018).

A atuação do advogado no exercício da sua profissão está intimamente ligada à configuração ético-moral que o tem como um ente pessoal. A ética e a moral possuem conotações similares. A ética constitui uma forma conceitual de comportamento, sendo entendida como uma corrente filosófica com objetivo prioritário de analisar o comportamento humano. A moral, por sua vez, consiste no estado social comportamental subjetivo, o que existe à primeira vista no comportamento humano e é inerente à sua conduta; é reconhecida como um conjunto de princípios, obrigações e limitações da conduta, valores e ideais pessoais (RAMOS, 2018).

Assim, a resposta para a necessidade de um código deontológico, pautado pelos princípios elementares da Constituição, parte da consideração do compromisso moral que o advogado deve ter, precisamente pela função social que representa. No exercício de sua função, o advogado não pode, em nenhum caso, colocar em risco a independência profissional, a lealdade e o sigilo profissional, comprometendo-se a atuar com honradez e diligência (RAMOS, 2018). 


\title{
3 A INDISPENSABILIDADE DA ADVOCACIA NA GARANTIA DO DEVIDO ACESSO À JUSTIÇA
}

$\mathrm{O}$ acesso à justiça está elencado no artigo $5^{\circ}$, inciso XXXV, da Constituição Federal, que diz: "a lei não excluirá da apreciação do Poder Judiciário lesão ou ameaça de direito".

O Estado moderno exerce três funções distintas, harmônicas entre si, correspondentes aos três poderes: Legislativo, Executivo e Judiciário. Assim, distribui o seu poder soberano: as funções legislativa, administrativa e jurisdicional do Estado (SANTOS, 2008, p. 89).

O Direito Processual Civil dedica-se ao estudo das normas jurídicas, voltadas à resolução de conflitos, isto é, estuda a forma de atuação de um dos poderes do Estado, o Judiciário, quando provocado para decidir conflitos de interesses entre mais de uma pessoa ou grupos de pessoas.

Segundo as lições de Mauro Cappelletti e Bryant Garth, a justiça deve ser igualmente acessível a todos e deve produzir resultados que sejam individual e socialmente justos. $\mathrm{O}$ acesso à justiça é direito fundamental básico dos direitos humanos. Embora o acesso à justiça venha sendo aceito como um direito social básico, sua efetividade ainda é algo que deixa a desejar, ou seja, algo vago:

\begin{abstract}
A efetividade perfeita, no contexto de um dado direito substantivo, poderia ser expressa como a completa "igualdade de armas" - a garantia de que a conclusão final depende apenas dos méritos jurídicos relativos das partes antagônicas, sem relação com diferenças que sejam estranhas ao Direito e que, no entanto, afetam a afirmação e reivindicação dos direitos. Essa perfeita igualdade, naturalmente, é utópica. As diferenças entre as partes não podem jamais ser completamente erradicadas. A questão é saber até onde avançar na direção do objetivo utópico e a que custo. Em outras palavras, quantos dos obstáculos ao acesso efetivo à justiça podem e devem ser atacados? A identificação desses obstáculos, consequentemente, é a primeira tarefa a ser cumprida. (CAPPELLETTI; GARTH, 1988, p. 15).
\end{abstract}

Esses dois autores abordaram soluções práticas para os problemas de acesso à justiça e intitularam essas soluções usando o termo "ondas".

A primeira "onda" ou solução para o acesso efetivo à justiça seria a assistência judiciária para os pobres, caso em que o auxílio de um advogado seria essencial, quando não indispensável, para decifrar leis e então ajuizar uma causa. Com o passar do tempo, as pessoas economicamente carentes obtiveram maior acesso à justiça e puderam reivindicar 
seus direitos, nas causas de família, nas causas criminais ou para reivindicar novos direitos (CAPPELLETTI; GARTH, 1988, p. 12).

A segunda "onda" ou solução versa sobre a representação dos direitos individuais, fase em que o processo era retratado apenas como uma controvérsia discutida pelas partes, que compareciam ao Judiciário para defender seus interesses particulares, não havendo espaço para discutir direitos difusos ou mesmo implicações sociais (CAPPELLETTI; GARTH, 1988, p. 18).

A terceira "onda" é o acesso à representação em juízo, um novo enfoque de acesso à justiça:

O progresso na obtenção de reformas da assistência jurídica e da busca de mecanismos para a representação de interesses "públicos" é essencial para proporcionar um significativo acesso à justiça. Essas reformas serão bem sucedidas - e, em parte, já o foram - no objetivo de alcançar proteção judicial para interesses que por muito tempo foram deixados ao desabrigo. Os programas de assistência judiciária estão finalmente tornando disponíveis advogados para muitos dos que não podem custear seus serviços e estão cada vez mais tornando as pessoas conscientes de seus direitos. (CAPPELLETTI; GARTH, 1988, p. 25).

Segundo o entendimento de Marcela de Almeida Pinheiro Braga:

O acesso à justiça pressupõe, sem embargo, a capacidade e oportunidade de realização de um direito, primordialmente dos direitos humanos, assim considerados os direitos civis, políticos e sociais, configuração leal e verdadeira da cidadania. Somente assim o sendo, se vislumbrará maior aproximação do que venha a ser o Direito como tentativa de construção do justo. (BRAGA, 2008, não paginado).

A autora lembra que o acesso à justiça não pode ser confundido com o acesso ao Judiciário:

É de ressaltar que acesso à justiça não se confunde, diga-se, não se deve confundir com acesso ao Judiciário. Este, tanto quanto a dignidade, é estranho ao povo, que não o consegue compreender, tampouco tocar, eis que possui linguagem própria, inacessível e demasiadamente rebuscada, apresenta-se com indumentária cerimoniosa, de modo a destacar seus operadores dos demais, seja quem for. É um universo impenetrável, diferente mesmo, e não por acaso, mas porque assim pretende ser, encharcado de formalidade e apaixonado pela hierarquização das relações, dos cargos e das pessoas. (BRAGA, 2008, não paginado). 
Todos têm, portanto, direito ao acesso à justiça, por se tratar de uma faculdade humanitária, prevista na Constituição Federal como garantia fundamental inerente à condição humana em sociedade. Neste ponto é que surge a importância da advocacia para garantir o efetivo acesso à justiça. O cidadão, ainda que não se possa valer do desconhecimento da lei, frente ao desestimulador cenário social brasileiro, criador de inúmeras dificuldades para a perpetuação do conhecimento de maneira geral, precisa da assistência jurídica dos profissionais e estudiosos que se especializaram nas áreas jurídicas de interesse coletivo e particular.

Essa assistência jurídica, apresentada por meio da assessoria, consultoria ou representação jurídica, são atividades específicas e privativas da advocacia e se apresenta ao cidadão como uma aliada na garantia do acesso à justiça não somente em seu sentido terminológico, mas em seu sentido literal.

\section{IMPLICAÇÕES DA INFORMATIZAÇÃO NA ADVOCACIA CONTEMPORÂNEA: COMO A MERCANTILIZAÇÃO DA ADVOCACIA DESESTIMULA O SENSO JURÍDICO CRÍTICO E A INDISPENSÁVEL ADMINISTRAÇÃO DA JUSTIÇA}

A modernização da sociedade fez com que a advocacia adentrasse em um novo contexto social, político e, principalmente, econômico. A forma de se apresentar ao mercado não se mantém mais como no período de início da vigência do Estatuto da Ordem dos Advogados do Brasil, o que é um risco inerente à mercantilização da profissão, que será abordada de forma mais específica posteriormente.

Neste item, tendo por base toda a evolução do exercício profissional ao longo do tempo, em diferentes cenários sociais, após lutas de classes e adequação constitucional, se faz necessário analisar a advocacia contemporânea, as implicações da informatização no exercício profissional, sobretudo, a falta de desenvolvimento do pensamento crítico, um dos principais fatores de evolução.

Atualmente, a advocacia possui um novo papel; mais do que representar os interesses particulares, o exercício profissional serve ao propósito social direto ao levar a informação jurídica para a população, em meio a tantas informações que se apresentam diariamente nas redes sociais. Ser advogado, no novo modelo conceptivo, é colaborar com os institutos jurídicos na busca da efetividade da justiça, principalmente através dos meios alternativos de resolução de conflitos. Segundo Rafaela Lopes Souza: 
A advocacia que visa a colaboração com os métodos consensuais de resolução de conflitos está presente na própria inspiração do Novo Código de Processo Civil, que já declara que o processo irá privilegiar as soluções consensuais. Lá fica claro que aquele espírito da litigância ficou para trás e que caberá a nós, advogados, utilizar o direito de forma mais ampla e, agora, modernizada pelo século XXI. (SOUZA, 2018, não paginado).

O problema é que, na prática, no sistema capitalista a advocacia, pela grande maioria, objetiva o fator econômico do lucro, retratando-se como um negócio, não mais como um exercício louvável de proteção à administração regular da justiça. Esse desvirtuamento de princípios morais e de deontologia ética é que, dia após dia, desestimula o pensamento crítico na profissão, o desenvolvimento jurídico e, por consequência, a própria evolução da classe, que passa a atuar de forma robotizada em prol do interesse particular.

Não se pode perder de vista os princípios mais elementares da advocacia, assim previstos pelo Estatuto da Advocacia:

Art. 31. O advogado deve proceder de forma que o torne merecedor de respeito e que contribua para o prestígio da classe e da advocacia.

$\S 1^{\circ} \mathrm{O}$ advogado, no exercício da profissão, deve manter independência em qualquer circunstância.

$\S 2^{\circ}$ Nenhum receio de desagradar a magistrado ou a qualquer autoridade, nem de incorrer em impopularidade, deve deter o advogado no exercício da profissão.

Art. 32. O advogado é responsável pelos atos que, no exercício profissional, praticar com dolo ou culpa.

Parágrafo único. Em caso de lide temerária, o advogado será solidariamente responsável com seu cliente, desde que coligado com este para lesar a parte contrária, o que será apurado em ação própria.

Art. 33. O advogado obriga-se a cumprir rigorosamente os deveres consignados no Código de Ética e Disciplina.

A importância do advogado no exercício da ampla defesa e do contraditório, pautada não só pelo positivismo ético, mas pela preservação moral, advém de muitas lutas democráticas até a atual concepção normativa, social, econômica e política que se apresenta. Para Ricargo Nery Falbo e Luiz Otávio Ribas, a independência da profissão permitiu que muitas pessoas garantissem o devido acesso à justiça em diferentes épocas vividas pela nação brasileira, ressaltando sua importância na luta pela garantia mínima aos escravos em diversos momentos sociais até sua libertação efetiva:

[...] a prática da defesa com base na verdade permite pensar a autonomia dos advogados - e certa liberdade para os escravos - segundo o espaço da 
contestação fosse efetivamente usado como espaço onde os escravos e os advogados dos mesmos contestassem a palavra dos senhores. Sem implicar a abolição das leis sociais, a contestação dos advogados pode ser vista como sendo o espaço de liberdade onde a defesa assumia função crítica quanto à necessidade de mudança no direito. Sem que jamais tenha suscitado a prática do crime de lesa-majestade, a liberdade de defesa resultava em forma de questionamento da legitimidade e legalidade da propriedade dos senhores, transformava a justiça em espaço de luta por garantia e ampliação de direitos, provocava escândalos e revelava segredos e intimidades dos senhores e constituía para os advogados fonte de atrito tanto pessoal quanto profissional. Daí não ser estranho que a hierarquia social oferecesse resistência diante do que poderia ser interpretado como sendo ausência de certo respeito decorrente da forma como os advogados revelavam maior ou menor distância entre eles próprios e entre os escravos e senhores. (FALBO; RIBAS, 2017, não paginado)

Não é de hoje, portanto, que a advocacia exerce o senso crítico. As lutas pela democracia emanaram da independência da profissão e capacidade de avaliar as implicações do meio ambiente social, assim como as violações e lacunas normativas que possibilitassem o abuso dos direitos. O pensamento crítico sempre foi forte aliado da advocacia no controle da discricionariedade da justiça, do Estado e de seus próprios membros. Contudo, como anteriormente apresentado, a advocacia contemporânea, na prática, busca muito mais satisfazer o interesse econômico privado do que desenvolver o sistema jurídico em si.

Com o desenvolvimento de novas tecnologias capazes de possibilitar melhor e mais ágil acessibilidade das partes e advogados aos processos, assim como melhor controle de atos, peticionamento e intimações, principalmente através do processo eletrônico e os softwares jurídicos que o sustentam, a advocacia se tornou muito mais integrativa e flexibilizada, desmistificando os anteriores modelos de escritórios que ora se apresentavam. Ao mesmo passo em que as redes sociais ganharam notoriedade, os advogados passaram a usá-las como forma de exposição do seu trabalho, do seu escritório, ou mesmo como forma de informar a população e possibilitar uma promoção profissional.

No entanto, a enorme quantidade de conteúdo exposto de todas as formas possíveis, muitas vezes sem uma criteriosa análise do senso crítico, acaba por, na verdade, desinformar a população e gerar verdadeira mercantilização da profissão, o que é expressamente vedado pela Resolução n. 02/2015 do Conselho Federal da Ordem dos Advogados do Brasil:

Art. 39. A publicidade profissional do advogado tem caráter meramente informativo e deve primar pela discrição e sobriedade, não podendo configurar captação de clientela ou mercantilização da profissão. 
(CONSELHO FEDERAL DA ORDEM DOS ADVOGADOS DO BRASIL, 1995)

Sobre a publicidade da advocacia, o Código de Ética e Disciplina não deixa dúvidas acerca da necessária moderação, discrição e finalidade informativa, o que segue em total contraposição à mercantilização:

Art. 28. O advogado pode anunciar os seus serviços profissionais, individual ou coletivamente, com discrição e moderação, para finalidade exclusivamente informativa, vedada a divulgação em conjunto com outra atividade. (CONSELHO FEDERAL DA ORDEM DOS ADVOGADOS DO BRASIL, 1995).

Os autores Clóvis Castelo Júnior e César Tureta afirmam que a advocacia passou por uma constante transformação a partir do ano de 1996, precisando adaptar-se à nova forma de exposição e disposição da sociedade:

O mercado de serviços advocatícios no país seguiu, até recentemente, um padrão praticamente homogêneo: grande pulverização, com predomínio do exercício liberal e autônomo, em escritórios de pequeno e médio porte (OAB, 1996). No entanto grandes transformações atingiriam o país, a partir do início da década de 1990, devido à abertura do mercado nacional, às privatizações de empresas públicas e terceirizações realizadas pelo governo brasileiro, além da entrada de novos e grandes investidores (Bonelli \& Barbalho, 2008). Esse quadro ampliou, de forma inédita, as oportunidades para o setor de prestação de serviços jurídicos, ao mesmo tempo em que obrigou os escritórios a assumirem uma postura modernizadora (Bonelli, 1998). O aumento da demanda de trabalho ampliou a busca por especialistas em áreas específicas do Direito, principalmente do ramo empresarial (Hapner, 2002; Pereira, 2008), bem como gerou um crescimento no número de escritórios. (CASTELO JUNIOR; TURETA, 2019, p. 818).

A informatização, ao tempo em que proporciona maior acessibilidade aos processos, além da facilidade de consulta, peticionamento e acompanhamento, induz o aumento do volume de trabalho dos advogados, que passam a tratar os casos particulares como instrumento de arrecadação econômica, a serem realizados da forma mais mecanizada possível, o que desvirtua o aludido pensamento crítico, que referendou a evolução da classe.

Sávio Cavalcante, ao traçar um comparativo entre o trabalho operário das indústrias e as mudanças trazidas pela informatização, possibilita uma melhor compreensão dos impactos na advocacia: 
Transformadas em linguagem de máquina, as ideias advindas das experiências vividas e formuladas pelos operários no dia-a-dia da produção ficam, desse modo, cristalizadas num supercomputador da empresa. Por conseguinte, a subjetividade dos trabalhadores, bem como seu saber-fazer, tornam-se trabalho morto do qual a empresa se apropria e se utiliza quando e como quiser. Sendo essa a recomendação, tanto faz se esse supercomputador seja real ou fictício. O importante é que os trabalhadores estejam agindo nesse sentido, pensando e produzindo ideias para o capital. (CAVALCANTE, 2007, p. 818).

$\mathrm{Na}$ verdade, o que realmente importa ao interesse particular do advogado, no cenário atual, é a forma de se relacionar com o cliente nesses tempos de grande inovação tecnológica. Nem poderia ser diferente, visto que é o cliente que possibilita ao advogado o exercício do peticionamento aos órgãos públicos. Comentando a transformação da advocacia com o avanço da tecnologia, Vanessa Massaro faz importantes considerações sobre a advocacia moderna:

Todo esse processo tecnológico obrigou os advogados a reorganizarem seus escritórios, pois cada vez menos se necessita de espaço físico, ou de pessoal que se dedique exclusivamente ao atendimento dos clientes, pois verifica-se que todos esses instrumentos não têm sido mais tão necessários como eram há tempos atrás; justamente por isso que a tecnologia deverá ser um aliado para que se possa criar outros tipos de profissionais que serão úteis em outros setores de mercado, como por exemplo, profissionais especializados em tecnologia e que possam atuar no meio jurídico também. Quando falamos nas novas tecnologias no sentido de como mudará a profissão forense e o trabalho do advogado com seu surgimento, não nos referimos apenas a internet, sites profissionais, Linkedin, redes sociais, pois esta é uma realidade com a qual todos estamos acostumados. (MASSARO, 2018, não paginado).

A autora segue dizendo que a tão comentada nova tecnologia se trata da inteligência artificial:

Essa nova tecnologia é a inteligência artificial, ou seja, a nova fronteira tecnológica que está sendo utilizada em alguns setores, como no caso da medicina, por exemplo. Os robôs agora aprendem com seus próprios erros, aprendem coisas novas e se desenvolvem, sendo capazes de serem mais capacitados e atentos que um ser humano. Mesmo que a advocacia seja uma categoria profissional ainda muito conservadora, pois a advocacia é uma atividade intelectual que não pode ser exercitada através de uma mentalidade organizativa empreendedora e o modelo "boutique" de escritório continua sendo o modelo tradicional por excelência para muitos, as coisas já estão mudando, e os fatos demonstram que a profissão forense não poderá ser exercida como antes, todavia isso não quer dizer que a qualidade na prestação dos serviços será menor, mas que os novos tempos imporão novos 
ritmos, novas competências e organização, isso se o profissional quiser manter-se competitivo. (MASSARO, 2018, não paginado).

O que causa preocupação, de fato, é o elevado índice de profissionais que já não conseguem preencher todos os espaços do mercado. Esse fenômeno resulta na mercantilização da profissão, possibilitada pela maior disseminação através da informatização, bem como em alarmante preocupação com os direitos e deveres morais e éticos estabelecidos, além do próprio senso crítico jurídico advindo da análise de cada caso concreto com particularidade.

Ao analisar-se o contexto social dos jovens advogados do estado do Rio Grande do Sul, conclui-se que há dualidade entre o acesso à educação e a inflação de mercado:

\begin{abstract}
Observa-se, portanto, que a atual conjuntura tem caráter dual: de um lado maior acesso à educação e à justiça por parte de camadas vulneráveis da população, de outro o aumento desenfreado de profissionais da advocacia no mercado, que gera um exército de reserva, que acaba por se submeter a vínculos informais de trabalho, com baixos salários e condições laborais abusivas. (MASSARO, 2018, não paginado).
\end{abstract}

Ao final, a autora pontua os principais elementos que podem resultar em uma crise procedimental da advocacia:

\begin{abstract}
A crise da advocacia tem portanto os seguintes elementos: (a) alta procura pelos cursos de direito devido a sua fama de alto retorno financeiro e grande prestígio social advindo do período imperial, (b) a baixa qualidade do ensino jurídico oferecido pelas faculdades de Direito, (b) (sic) a mercantilização do ensino e aumento exponencial de faculdades de Direito no país, (c) as iniciativas neoliberais de ordem global, traduzidas na advocacia com o surgimento de empresas jurídicas e na flexibilização e informalidade no mercado de trabalho advocatício, (d) alienação ética e moral, tanto da função social da profissão, como na exploração de mão de obra de maneira ilegal pelos próprios colegas de profissão e omissão destas pela própria categoria. (MASSARO, 2018, não paginado).
\end{abstract}

A informatização da advocacia é, portanto, forte aliada para o desenvolvimento da profissão, possibilitando celeridade não só para a profissão em particular, mas parta a entrega da prestação jurisdicional efetiva e, desse modo, para as partes, garantindo-se o consagrado princípio da razoabilidade. Com o avanço tecnológico, aumentou-se o volume de trabalho dos advogados, que puderam concentrar um número maior de processos simultâneos, ao tempo em que se possibilitou maior acessibilidade à educação através dos cursos de Direito, que se tornaram grandes atrativos. Não se pode fechar os olhos, no entanto, ao fato de que referidos 
fatores resultam em uma mercantilização da atividade, o que permanece contra os preceitos mais elementares de uma profissão formada por lutas de ideais morais e preceitos éticos.

\section{CONSIDERAÇÕES FINAIS}

Conforme proposta, o artigo teve por objetivo analisar, pesquisar e detalhar elementos da modernização da advocacia através da flexibilização da profissão no cenário contemporâneo, resultado do avanço da tecnologia e da informatização, ao tempo em que se buscou demonstrar as implicações do Estatuto da Advocacia na nova forma em que a atividade se apresenta, além da importância da preservação do pensamento crítico, sem expor uma eventual mercantilização.

Como resposta ao questionamento apresentado inicialmente, tem-se que as implicações da Lei n. 8.906/94 são efetivas na exposição da advocacia moderna em razão da flexibilização do advogado contemporâneo, mas ainda não conseguem sustentar a manutenção do pensamento crítico, ameaçado pelo elevado volume de trabalho que se tornou possível pelo processo de informatização que a sociedade vive.

É possível supor, então, que a flexibilização do advogado contemporâneo ante as implicações da Lei n. 8.906/94 é fundamental para a preservação do pensamento crítico na advocacia moderna.

Inicialmente, analisou-se o histórico da advocacia no Brasil e como a figura do advogado era retratada no período Brasil-Império. Com a emancipação e conquista da independência profissional através da criação do Instituto dos Advogados do Brasil, a regularização da profissão passou a resultar em maior garantia da aplicação da lei e em julgamentos mais justos.

Seguidamente, tratou-se de analisar os desafios enfrentados pela advocacia no contexto nacional, sobretudo os fatores que resultaram na participação da $\mathrm{OAB}$ e das associações nas lutas em prol da democracia e das garantias mínimas que viriam a ser positivadas na Constituição da República Federativa do Brasil de 1988. As lutas foram de fundamental importância para a atual concepção do processo moderno, alicerçado por uma série de princípios institucionais voltados à norma processual e sustentados pelos princípios constitucionais que protegem as garantias mínimas.

Analisaram-se ainda as implicações da nova carta constitucional no Estatuto da Advocacia e a necessária adequação deste ao contexto social, político e jurídico vivenciado a 
partir desse ponto. A nova previsão constitucional foi muito mais adequada ao anseio social pela democracia, fruto de grandes movimentos sociais vivenciados antes da sua vigência.

Subsequentemente, abordou-se a importância da advocacia como instrumento para garantia do acesso à justiça, não apenas no sentido figurativo do termo, mas em seu sentido literal, materializado através da entrega de uma prestação jurisdicional satisfatória e justa, baseada nos fatos, elementos de fato e elementos jurídicos que cada caso em particular apresenta.

Foi possível perceber que a advocacia é, de fato, indispensável para preservação dos princípios e garantias mínimas, porque a especialização da atividade jurídica, em meio a tantos dispositivos normativos e precedentes, possibilita até mesmo ao cidadão mais leigo a segurança de um processo igualitário e justo, através do senso crítico do causídico que o representa.

A grande questão é que justamente esse tão necessário senso crítico tem sobrevida questionada no ordenamento social, uma vez que, por diversos fatores, a advocacia moderna passa por um processo estrutural de mercantilização em prol do volume de trabalho e busca pelo crescente número de clientes. $\mathrm{O}$ aumento de trabalho tende $\mathrm{a}$, junto à informatização, resultar em uma advocacia mecanizada, robotizada, que não valoriza o senso crítico e democrático do processo, mas sim o acúmulo de contratações que garantam a manutenção do inicial interesse financeiro em uma profissão tão prestigiada.

O presente artigo não visou esgotar o tema proposto, mas analisar a advocacia existente no contexto social brasileiro atual, distinta da advocacia clássica, que buscava a análise de cada caso particular, baseada no enfrentamento jurídico. A grande questão, de fato, é que o acúmulo de profissionais que emanam anualmente de cursos jurídicos, muitas vezes sem a formação crítica que a profissão exige e voltados apenas ao propósito financeiro do lucro, induz à mercantilização da profissão, alicerceada pela facilidade propiciada pela informatização.

\section{REFERÊNCIAS}

BRAGA, Marcela de Almeida Pinheiro. Acesso à Justiça não se confunde com acesso ao Judiciário. Revista Consultor Jurídico, sem página, 11 out. 2008. Disponível em: https://www.conjur.com.br/2008-out-11/acesso_justica_nao_confunde_acesso_judiciario. Acesso em: 29 maio 2019. 
BRASIL. [Constituição (1988)]. Constituição da República Federativa do Brasil de 1988. Brasília, DF: Presidência da República, 1988. Disponível em: http://www.planalto.gov.br/ccivil_03/constituicao/constituicao.htm. Acesso em: 29 maio 2019.

Lei $\mathrm{n}^{\circ}$ 8.906, de 4 de julho de 1994. Dispõe sobre o Estatuto da Advocacia e a Ordem dos Advogados do Brasil (OAB). Brasília, DF: Presidência da República, 1994. Disponível em: http://www.planalto.gov.br/ccivil_03/Leis/L8906.htm. Acesso em: 1 jun. 2019.

CAPPELlETTI, Mauro; GARTH, Bryant. Acesso à justiça. Tradução Ellen Gracie Northfleet. Porto Alegre: Fabris, 1988.

CAVALCANTE, Sávio. Informatização do trabalho e reificação: uma análise à luz dos programas de qualidade total. Revista Lutas Sociais da Pontifica Universidade Católica de São Paulo, n. 17/18, ISSN 2526-3706, São Paulo, 2007. Disponível em: https://revistas.pucsp.br/index.php/ls/article/view/18716. Acesso em: 29 maio 2019.

CONSELHO FEDERAL DA ORDEM DOS ADVOGADOS DO BRASIL. Código de ética e disciplina da OAB. Brasília, DF: OAB, 1995. Disponível em: https://www.oab.org.br/visualizador/19/codigo-de-etica-e-disciplina. Acesso em: 29 maio 2019.

Resolução no 02, de 19 de outubro de 2015. Brasília, DF: OAB, 2015. Disponível em: https://www.migalhas.com.br/arquivos/2015/11/art20151104-01.pdf. Acesso em: 29 maio 2019.

CUNHA, Sérgio Sérvulo da. História da advocacia no Brasil. 2005. Disponível em: http://www.servulo.com.br/pdf/advocacia.pdf. Acesso em: 25 maio 2019.

D’ÁVILA, Thiago Cássio. História da advocacia e da OAB no Brasil. In: BuscaLegis, 29 abril 2006. Disponível em: http://www.egov.ufsc.br/portal/sites/default/files/anexos/2680926811-1-PB.html. Acesso em: 25 maio 2019.

FALBO, Ricerdo Nery; RIBAS, Luiz Otávio. Advocacia e lutas emancipatórias: o que há de político na advocacia? Revista Direito e Práxis, Rio de Janeiro, v. 8, n. 1, jan/mar 2017. Disponível em: http://www.scielo.br/scielo.php?script=sci_arttext\&pid=S217989662017000100507\&lang=pt. Acesso em: 25 maio 2019.

JUNIOR, Clóvis Castelo; TURETA, César. A nova advocacia pós-profissional e a modernização das grandes sociedades de advocacia empresarial brasileiras. Revista de Administração Contemporânea, v. 23, n. 3, mai/jun 2019. Disponível em: http://www.scielo.br/pdf/rac/v18n6/1982-7849-rac-18-6-0813.pdf. Acesso em: 25 maio 2019.

MADEIRA, Hélio Maciel França. História da Advocacia. São Paulo: Revista dos Tribunais, 2002.

MASSARO, Vanessa. As novas tecnologias e os desafios da advocacia moderna, Revista Eletrônica Jus, jul. 2018. Disponível em: https://jus.com.br/artigos/67674/as-novastecnologias-e-os-desafios-da-advocacia-moderna. Acesso em: 26 maio 2019. 
RAMOS, Emilia Santana. El rol del abogado ante la ética y el ejercicio profesional. Revista de la Facultad de Derecho, Montevideo, n. 44, ISSN 2301-0665, jun. 2018. Disponível em: http://www.scielo.edu.uy/scielo.php?script=sci_arttext\&pid=S230106652018000100143\&lang=pt. Acesso em: 26 maio 2019.

RAMOS, Gisela Gondim. Estatuto da Advocacia: comentários e jurisprudência selecionada. 4. ed. Florianópolis: OAB/SC Editora, 2003.

SANTOS, Moacyr Amaral. Primeiras linhas de direito processual civil. 25 ed. São Paulo: Saraiva, 2008.

SOUZA, Rafaela Lopes. A advocacia do século XXI. In: MIGALHAS, 16 abril 2018. Disponível em: https://www.migalhas.com.br/dePeso/16,MI278310,41046A+Advocacia+do+Seculo+XXI. 